\title{
PENERAPAN IOT UNTUK SISTEM KENDALI JARAK JAUH PERALATAN LISTRIK RUMAH TANGGA BERBASIS RASPBERRY PI
}

\author{
Ketut Udy Ariawan \\ Teknik Elektronika, Universitas Pendidikan Ganesha \\ Singaraja, Indonesia \\ e-mail: udyariawan@undiksha.ac.id
}

\begin{abstract}
Abstrak
Perkembangan internet pada masa sekarang sangatlah pesat. Ketergantungan masyarakat terhadap internet sangat tinggi, terutama digunakan sebagai sumber pencarian informasi dan berbagai macam media sosial. Namun, saat ini penggunaan internet tidak hanya terpaku pada pencarian informasi dan media sosial saja, akan tetapi dapat juga digunakan untuk menghubungkan dan mengendalikan satu perangkat dengan perangkat lainnya tanpa campur tangan manusia. Teknologi ini disebut dengan Internet of Things (IOT). Salah satu perangkat yang sering dikendalikan menggunakan internet adalah peralatan listrik rumah tangga. Listrik saat ini juga menjadi kebutuhan dasar masyarakat. Namun, masyarakat juga sering mengeluh tentang biaya pembayaran listrik yang semakin mahal setiap bulannya. Hal ini disebabkan karena masyarakat sering lupa mematikan listrik sebelum pergi meninggalkan rumah. Dengan melihat permasalahan tersebut, maka dibuatlah sebuah alat yang mampu mematikan dan menghidupkan peralatan listrik rumah tangga dari jarak jauh melalui internet. Alat ini menggunakan Raspberry $\mathrm{Pi}$, Relay, dan Platform Cayenne yang dipasangkan pada Smartphone Android.
\end{abstract}

Kata kunci: internet of things, raspberry pi, relay, cayenne

\begin{abstract}
The development of the internet today is very rapid. Community dependence on the internet is very high, mainly used as a source of information search and various kinds of social media. However, at present the use of the internet is not only focused on searching for information and social media, but can also be used to connect and control one device with another without human intervention. This technology is called the Internet of Things (IOT). One device that is often controlled using the internet is household electrical appliances. Electricity is now also a basic need of the community. However, people also often complain about the cost of paying electricity which is getting more expensive every month. This is because people often forget to turn off electricity before leaving home. By looking at these problems, then made a tool that is able to turn off and turn on household electrical equipment remotely via the internet. This tool uses the Raspberry Pi, Relay, and the Cayenne Platform that is paired on an Android Smartphone.
\end{abstract}

Keywords : internet of things, rapsberry pi, relay, cayenne

\section{PENDAHULUAN}

Perkembangan teknologi berjalan seiring dengan perkembangan dunia. Saat ini, dunia internet telah mengalami perkembangan yang sangat pesat terutama pada bidang bisnis, pendidikan, hiburan, industri, dan lain-lain. Pada bidang-bidang tersebut internet digunakan sebagai media untuk membantu pekerjaan manusia. Internet memiliki berbagai macam fungsi seperti fungsi komunikasi, pertukaran data, media pencari informasi dan masih banyak lagi. Salah satu fungsi internet yang paling banyak digunakan oleh penggunanya 
adalah sebagai sumber informasi. Dengan internet mereka bisa mendapatkan informasi dengan cepat dan mudah. Selain sebagai sumber informasi, internet saat ini juga banyak digunakan sebagai sarana dalam bermedia sosial. Banyak aplikasi media sosial yang digunakan di Indonesia, seperti Youtube, Facebook, Instagram, Twitter, WhatsApp, Line, LinkedIn, dan lainlain.

Namun, saat ini penggunaan internet tidak hanya terpaku pada pencarian informasi dan media sosial saja, akan tetapi dapat juga digunakan untuk menghubungkan dan mengendalikan satu perangkat dengan perangkat lainnya tanpa campur tangan manusia. Teknologi ini disebut dengan Internet of Things (IoT).

IoT merupakan sebuah konsep dengan tujuan untuk memperluas konektivitas jaringan internet yang terhubung dengan jaringan global. IoT dimanfaatkan untuk mengendalikan peralatan-peralatan elektronik, seperti lampu dengan jarak jauh melalui jaringan internet secara global [1].

IoT memungkinkan interaksi antara mesin yang satu dengan mesin lainnya (M2M, machine to machine) seperti peralatan elektronik rumah tangga, sensor dan actuator, dan smartphone/computer. IoT dapat bekerja dengan baik memerlukan tiga hal berikut, yaitu pemahaman bersama terhadap pengguna dan aplikasinya, arsitektur software dan jaringan komunikasi untuk memproses dan menyalurkan informasi, dan perangkat analisis yang bertujuan untuk keperluan otomatisasi dan kemampuan cerdas [2].

Salah satu perangkat yang sering dikendalikan menggunakan loT adalah peralatan listrik rumah tangga. Listrik saat ini juga menjadi kebutuhan dasar masyarakat. Aktivitas masyarakat kini semakin meningkat menyebabkan masyarakat sering pergi meninggalkan rumah, sehingga seseorang akan mengalami kesulitan berinteraksi dengan peralatan listrik yang ada di rumah mereka. Hal ini tentunya akan menyita waktu dan akan membuang energi listrik dengan sia-sia, sehingga dapat berdampak pada beban biaya listrik yang saat ini semakin mahal.

Dengan melihat permasalahan tersebut, maka dibuatlah sebuah alat yang mampu mematikan dan menghidupkan peralatan listrik rumah tangga dari jarak jauh melalui internet. Alat ini menggunakan mikrokomputer Raspberry $\mathrm{Pi} 3$ sebagai kontrol utama (server), Modul Relay 4 Channel sebagai output dari mikrokomputer untuk mengendalikan perangkat listrik rumah tangga, dan Platform Cayenne yang dipasangkan pada Smartphone Android.

\section{Kajian Teori}

Pada pembuatan alat sistem kendali jarak jauh peralatan listrik rumah tangga ini menggunakan Rasperry $\mathrm{Pi} 3$ sebagai kontrol utama (server) untuk mengendalikan modul Relay 4 channel yang terhubung dengan instalasi listrik rumah tangga yang akan dikontrol.

Peralatan listrik yang ada di dalam rumah dapat dikendalikan melalui komputer maupun smartphone yang telah terkoneksi internet. Untuk pengendalian listrik rumah dari laptop hanya masuk melalui website dan listrik langsung dapat dikontrol, sedangkan untuk pengendalian listrik rumah dari smartphone melalui sebuah aplikasi atau platform Cayenne yang telah dipasangkan pada smartphone tersebut.

\section{a. Internet of Things (IoT)}

Internet of Things (IoT) merupakan sebuah konsep dimana perangkat tertentu memiliki kemampuan untuk dapat saling berkomunikasi dengan perangkat lain melalui sebuah jaringan tanpa memerlukan adanya interaksi atau campur tangan manusia.

Dalam penggunaannya loT banyak ditemui dalam berbagai aktifitas, seperti banyaknya transportasi online, ecommerce, pemesanan tiket secara online, live streaming, e-learning dan lainlain bahkan sampai alat-alat untuk membantu pada bidang tertentu seperti remot temperatur sensor, GPS tracking, dan sebagainya yang menggunakan 
internet atau jaringan sebagai media untuk melakukannya [3].

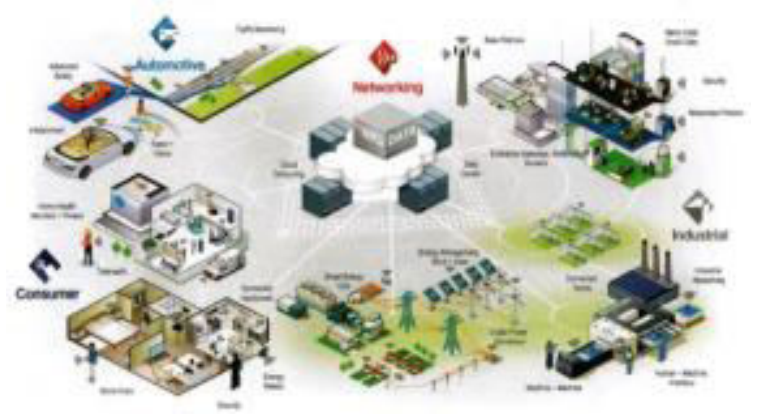

Gambar 1. Internet of Things (IoT)

\section{b. Raspberry Pi}

Seiring dengan pesatnya perkembangan teknologi, penggunaan komputer desktop mulai tergantikan keberadaannya dengan single board computer (salah satunya Raspberry Pi atau sering disebut Raspi) yang dianggap lebih praktis dan lebih hemat energi dalam penggunaannya [4].

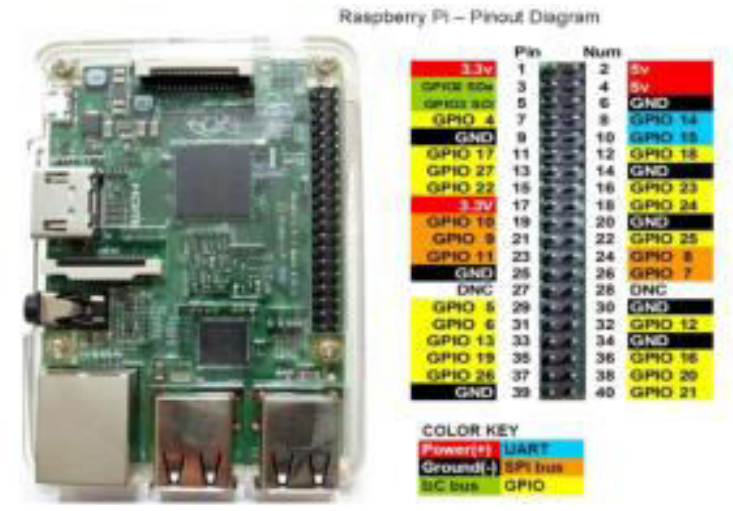

Gambar 2. Raspi dan Konfigurasi Pin GPIO

GPIO (General Purpose Input/Output) merupakan sederet pin yang terdiri dari 40 pin dengan berbagai fungsi yang terdapat dalam board Raspi. GPIO merupakan antarmuka fisik antara Raspi dengan perangkat lainnya. Pada tingkat yang paling sederhana, pin GPIO Raspi dapat dianggap sebagai switch yang dapat mengaktifkan atau menonaktifkan input maupun output.

Dari 40 pin, 26 pin GPIO dan yang lain adalah pin power atau ground (ditambah dua pin ID EEPROM yang tidak harus digunakan). Input tidak harus berasal dari sakelar fisik, itu bisa menjadi masukan dari sensor atau sinyal dari komputer atau perangkat lain. Output juga dapat berupa apa saja, bisa untuk menyalakan LED maupun mengirim sinyal atau data ke perangkat lain.

Raspi juga dapat digunakan pada jaringan, biasanya berfungsi untuk mengontrol perangkat lain secara jarak jauh dan perangkat lain tersebut juga dapat mengirim data kembali ke Raspi.

\section{c. Relay}

Relay merupakan suatu perangkat yang bekerja menggunakan prinsip elektromagnetik untuk menggerakkan sejumlah kontaktor yang tersusun atau sebuah saklar elektronis yang dapat dikendalikan dari rangkaian elektronik lainnya dengan memanfaatkan arus listrik yang kecil (low power) sebagai sumber energinya dapat menghantarkan listrik yang bertegangan lebih tinggi.

Secara prinsip, Relay merupakan tuas saklar dengan lilitan kawat pada batang besi (solenoid) di dekatnya. Ketika solenoid dialiri arus listrik, tuas akan tertarik karena adanya gaya magnet yang terjadi pada solenoid sehingga kontak saklar akan menutup. Pada saat arus listrik dihentikan, gaya magnet akan hilang, tuas akan kembali ke posisi semula dan kontak saklar kembali terbuka [5].
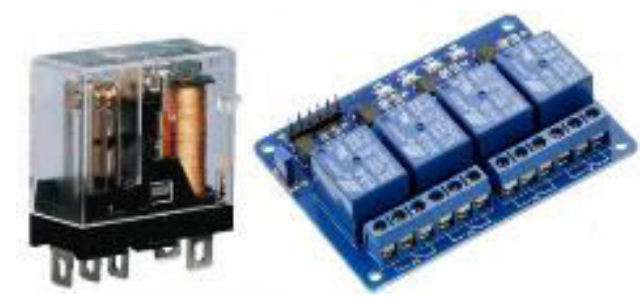

Gambar 3. Relay Sederhana dan Relay 4 Channel

\section{d. Cayenne}

Cayenne merupakan sebuah platform pengembangan dengan sistem drag-anddrop milik myDevices yang dibangun dengan tujuan untuk mempermudah penerapan teknologi loT, menyediakan set alat yang dapat digunakan untuk memvisualisasikan data yang diperoleh dari sensor, maupun mengendalikan aktuator 
yang terhubung dengan layanan, melalui web dashboard ataupun aplikasi mobile.

Platform Cayenne dapat juga digunakan untuk membangun peringatan dan pemicu antara dua platform board yang akan digunakan. Pada platform pengembangan ekosistem loT ini juga diberikan kemudahan untuk membuat widget baru untuk sensor ataupun aktuator yang terkoneksi dengan layanan [6][12363079-1-PB].

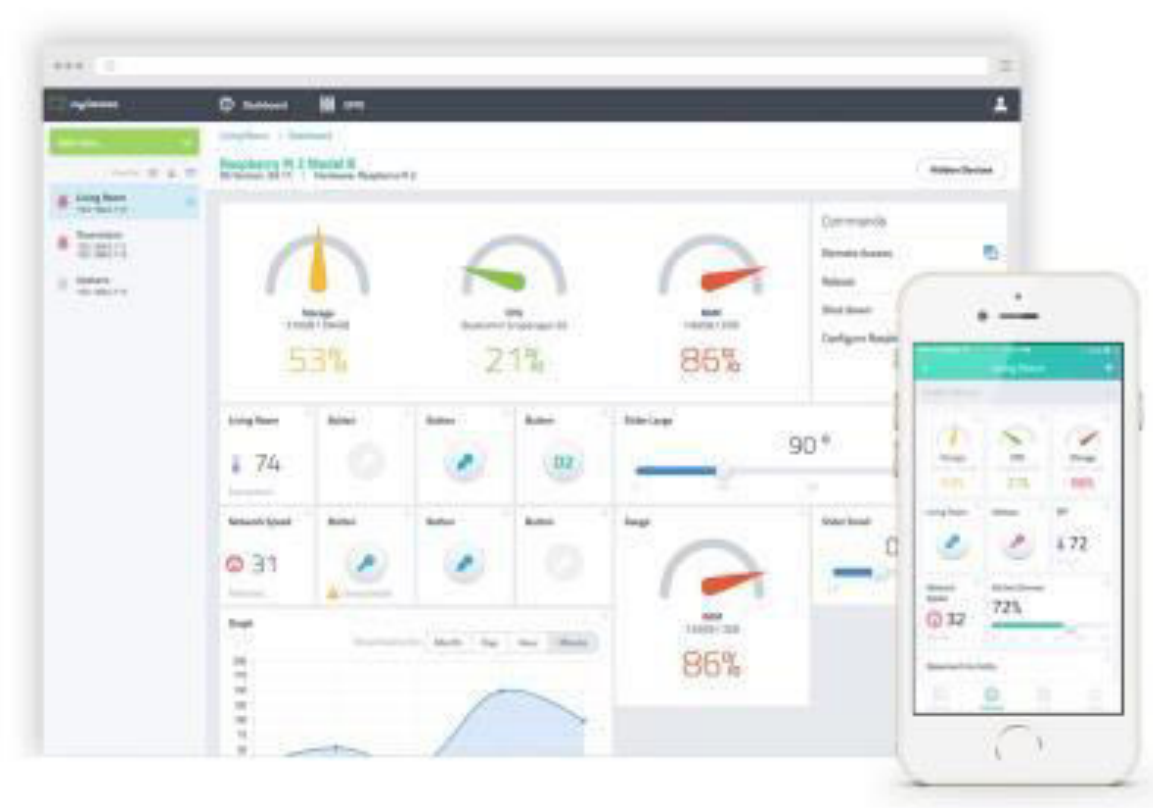

Gambar 4. Platform Cayenne

\section{METODE}

Metode-metode yang digunakan dalam pengumpulan data pada penelitian ini dilakukan dengan cara sebagai berikut:

Metode kepustakaan, yaitu penulis mengambil referensi dari jurnal-jurnal nasional (ISSN) yang telah publish dan sumber informasi lainnya di internet yang berkaitan dengan teori-teori yang dijadikan acuan pada penelitian ini.

Metode pengujian, yaitu dilakukan melalui smartphone (cayenne) dan melalui komputer (website). Pada saat salah satu tombol (button) pada website (untuk komputer) atau pada cayenne (untuk smartphone) ditekan, maka perintah (sinyal) yang dikirim menuju Raspi akan di proses, kemudian Raspi mengirim sinyal perintah ke Relay untuk dijalankan, sehingga pada saat
Relay menjalankan perintah, Relay bisa menghubungkan atau memutus arus ke beban (lampu).

Metode analisis data, yaitu dilakukan dengan cara mengukur tegangan keluaran masing-masing pin GPIO Raspi (Vdc) yang terhubung dengan input Relay, dan juga mengukur tegangan keluaran dari output Relay (Vac) yang terhubung dengan lampu. Alat ukur yang digunakan berupa Avometer dan Tang Ampere.

Pada penelitian ini juga dilakukan beberapa tahapan-tahapan yang harus diikuti agar dalam proses pembuatan alat sistem kendali jarak jauh peralatan listrik rumah tangga ini menjadi lancar dan tujuan dari penelitian dapat tercapai, yaitu dengan pembuatan diagram alir (flowchart). 


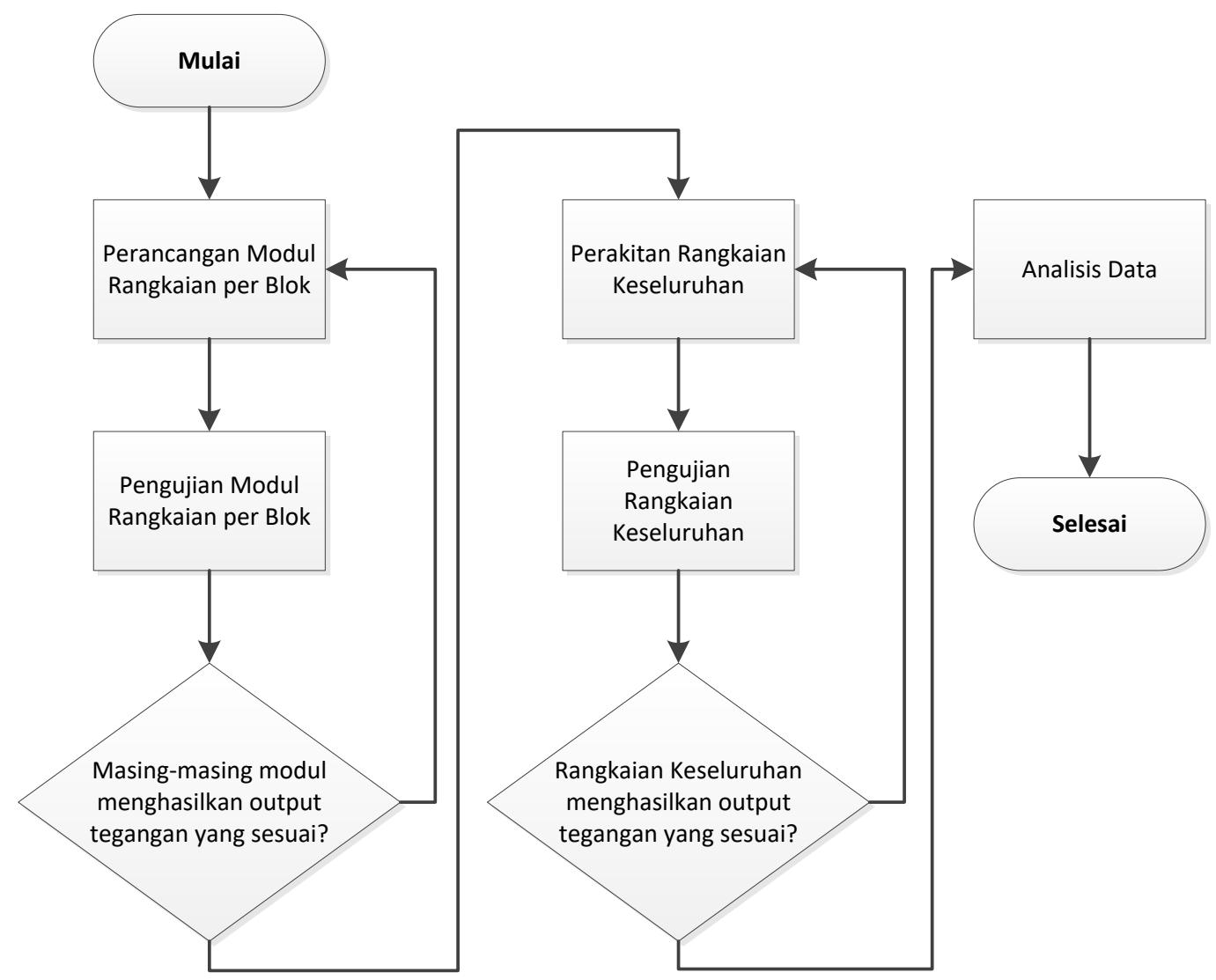

Gambar 5. Diagram Alir (Flowchart)

Sebelum dilakukan pembuatan alat sistem kendali jarak jauh peralatan listrik rumah tangga yang sebenarnya, maka sebelumnya dilakukan perancangan blok diagram rangkaian keseluruhan dan perancangan wiring skema diagram sistem rangkaian keseluruhan sebagai berikut:

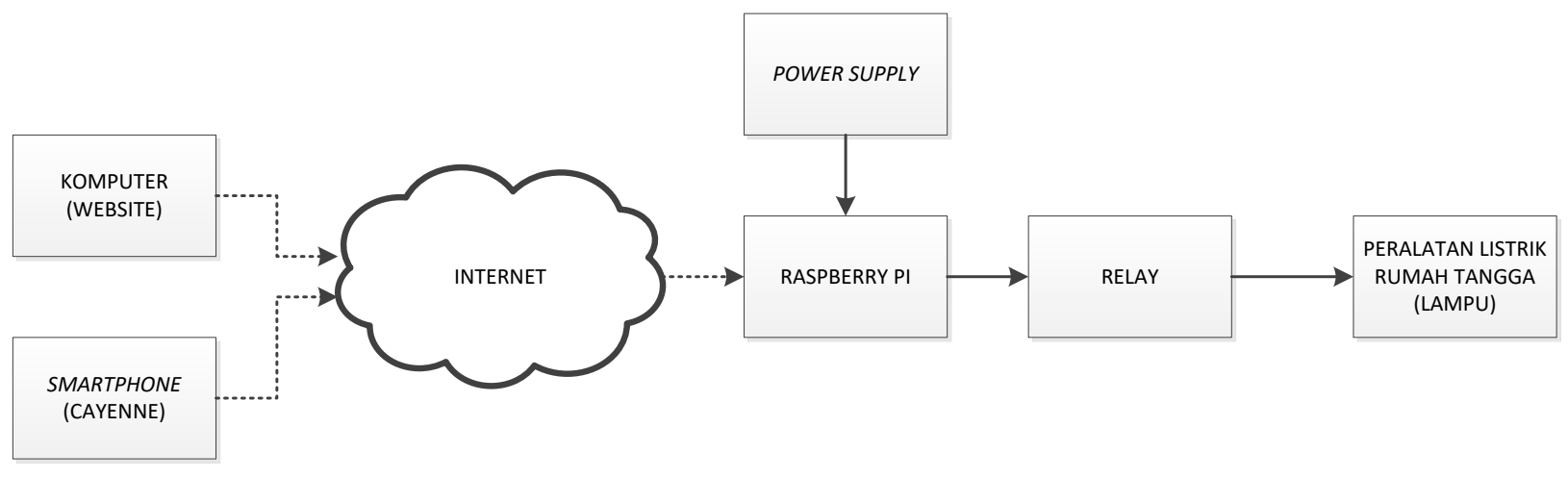

Gambar 6. Perancangan Blok Diagram Rangkaian Keseluruhan 


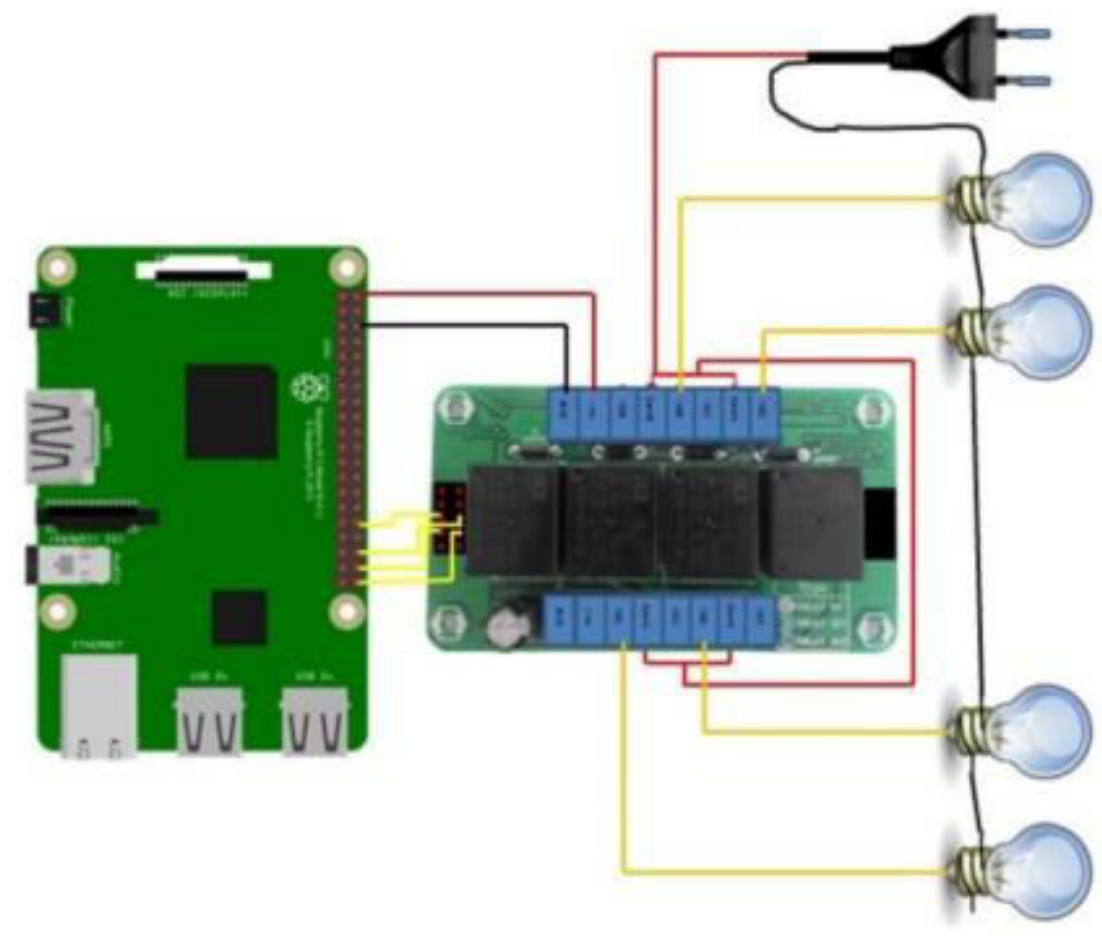

Gambar 7. Perancangan Wiring Skema Diagram Sistem Rangkaian Keseluruhan

Berikut ini penjelasan mengenai wiring skema diagram sistem rangkaian keseluruhan tersebut:

1. Dibuatkan kotak kontak untuk adaptor (sebagai sumber tegangan Raspi) dan penyuplai tegangan AC 220 Volt untuk menghidupkan peralatan listrik rumah tangga, seperti lampu.

2. Pin GPIO yang digunakan adalah pin VCC yang terhubung ke pin VCC Relay, pin GND terhubung dengan pin GND Relay, pin GPIO 18 terhubung ke pin IN 1 Relay, pin GPIO 17 terhubung ke pin IN 2 Relay, pin GPIO 27 terhubung ke pin IN 3 Relay, dan pin GPIO 22 terhubung ke pin IN 4 Relay.

3. Untuk COM setiap Relay terhubung satu sama lainnya ke salah satu kabel sumber AC 220 Volt, sedangkan untuk NO (Normally Open) Relay 1 terhubung dengan kabel untuk ke beban 1, untuk NO (Normally Open)
Relay 2 terhubung dengan kabel untuk ke beban 2, untuk NO (Normally Open) Relay 3 terhubung dengan kabel untuk ke beban 3, untuk NO (Normally Open) Relay 4 terhubung dengan kabel untuk ke beban 4.

4. Untuk setiap satu kabel beban terhubung satu sama lainnya ke salah satu kabel sumber AC 220 Volt, akan tetapi tidak boleh terhubung pada COM Relay yang sudah digunakan.

\section{HASIL DAN PEMBAHASAN}

Setelah dilakukan perancangan blok diagram rangkaian keseluruhan dan perancangan wiring skema diagram sistem rangkaian keseluruhan maka dihasilkan sebuah alat sistem kendali jarak jauh peralatan listrik rumah tangga yang sebenarnya sebagai berikut: 


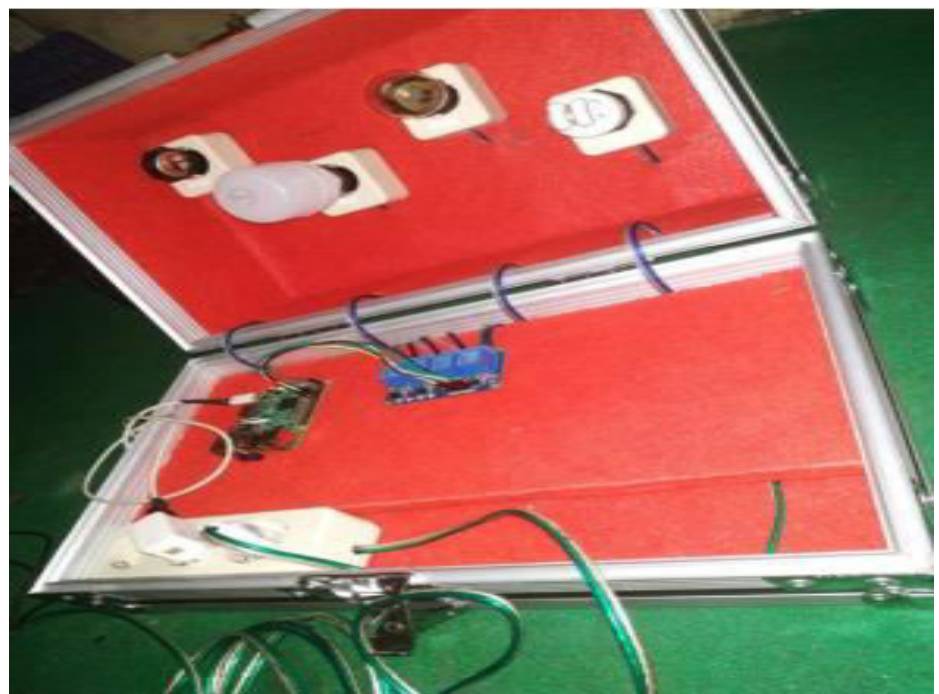

Gambar 8. Desain Rangkaian Keseluruhan

Tahap selanjutnya, yaitu melakukan pengujian dan pengambilan data. Beberapa pengujian yang dilakukan meliputi:

1. Pengujian melalui smartphone dan melalui komputer
a. Pengujian pada Raspi
b. Pengujian pada Relay

2. Pengujian keseluruhan sistem

Pengujian melalui smartphone dilakukan dengan cara memasang platform Cayenne pada smartphone berbasis Android atau bisa juga menggunakan smartphone berbasis iOS. Cayenne dapat diunduh pada playstore untuk smartphone berbasis Android atau dapat diunduh melalui App Store untuk smartphone berbasis iOS.

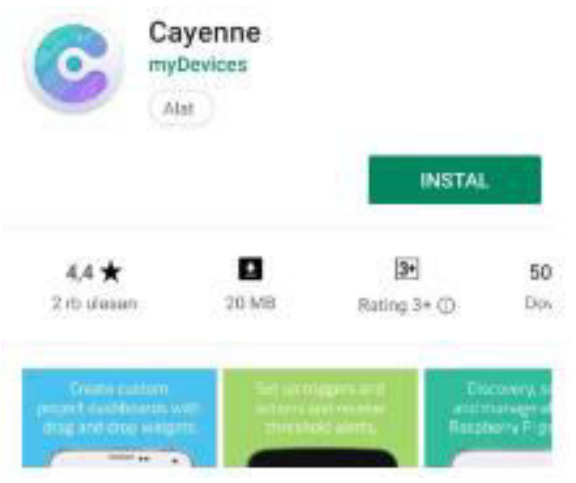

Gambar 9. Pemasangan Cayenne pada Smartphone
Setelah Cayenne berhasil dipasangkan pada smartphone, langkah selanjutnya, yaitu pembuatan akun, yang nantinya akan digunakan untuk login agar bisa mengakses Raspi secara online. Sesudah login dengan akun yang telah dibuat, pilihlah perangkat Rasi dan pastikan Raspi sudah dalam on dan terkoneksi dengan internet agar dapat dideteksi pada saat pencarian perangkat.

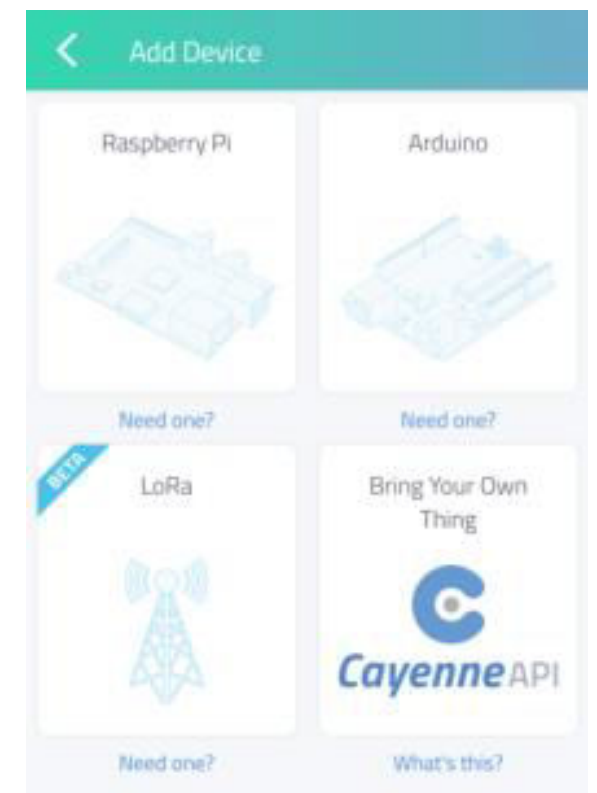

Gambar 10. Penambahan Perangkat Raspi pada Cayenne

Setelah penambahan perangkat yang diinginkan sudah dilakukan, selanjutnya 
lakukan perintah searching. Masukkan $\mathrm{SSH}$ username dan SSH password dari Raspi. Username dan password standar (default) dari SSH Raspi, yaitu "pi" merupakan username dan "raspberry" untuk password.

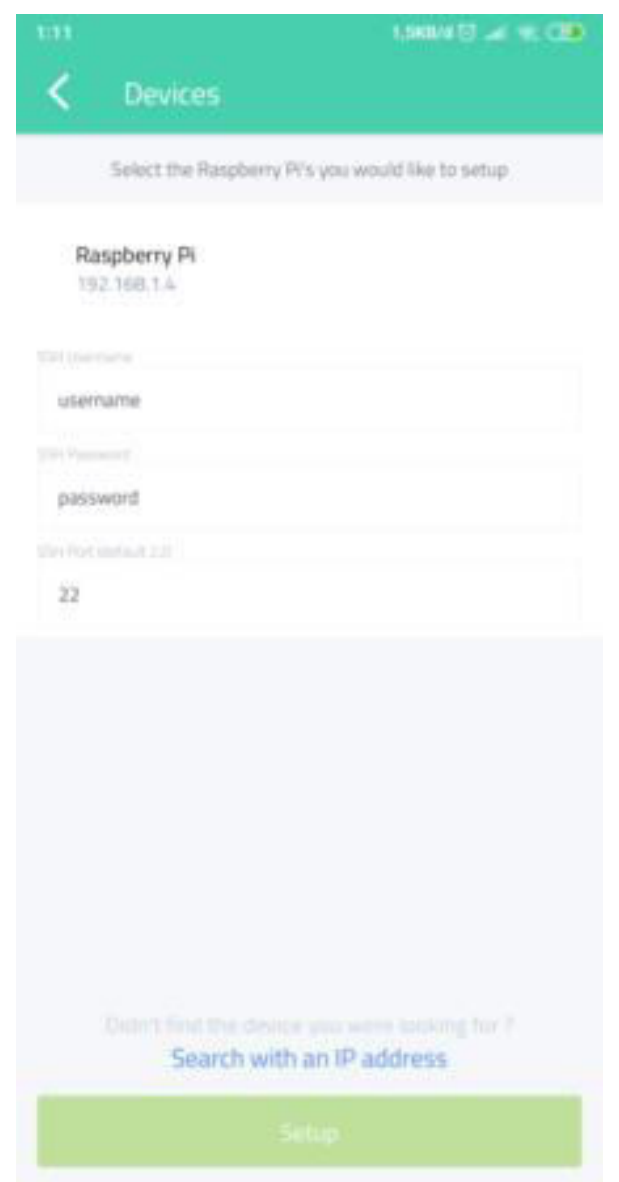

Gambar 11. Memasukkan SSH Raspi pada Cayenne

Setelah masuk ke dalam Raspberry Pi MQTT menu, maka ditampilkan informasi dari kondisi Raspi yang telah terhubung secara online.

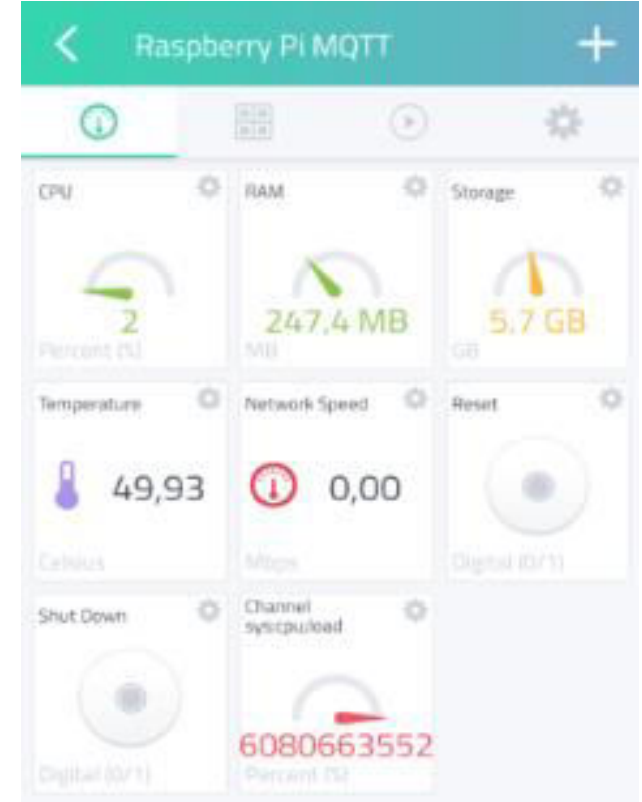

Gambar 12. Tampilan Monitoring Kondisi Raspi secara Online

Selanjutnya dilakukan penambahan device yang terhubung dengan Pin GPIO Raspi, yaitu dengan cara memilih tanda $(+)$ pada ujung kanan atas.

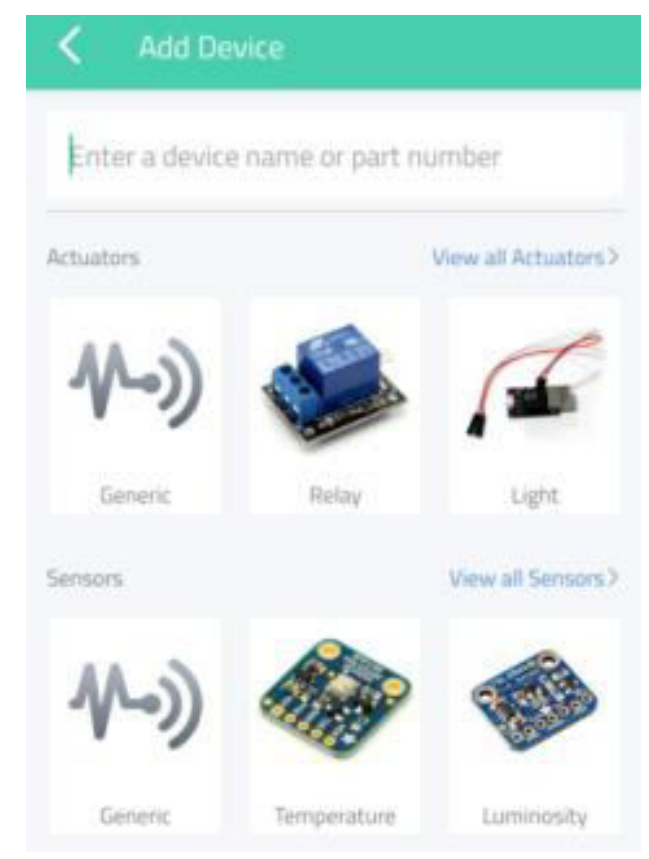

Gambar 13. Penambahan Device yang Terhubung dengan PIN GPIO Raspi 
Berdasarkan gambar diatas pilihlah Relay, karena ouput yang digunakan di pin GPIO adalah Relay. Relay yang digunakan berupa Relay 4 channel, jadi akan dibuat 4 perintah untuk mengoperasikan setiap Relay.

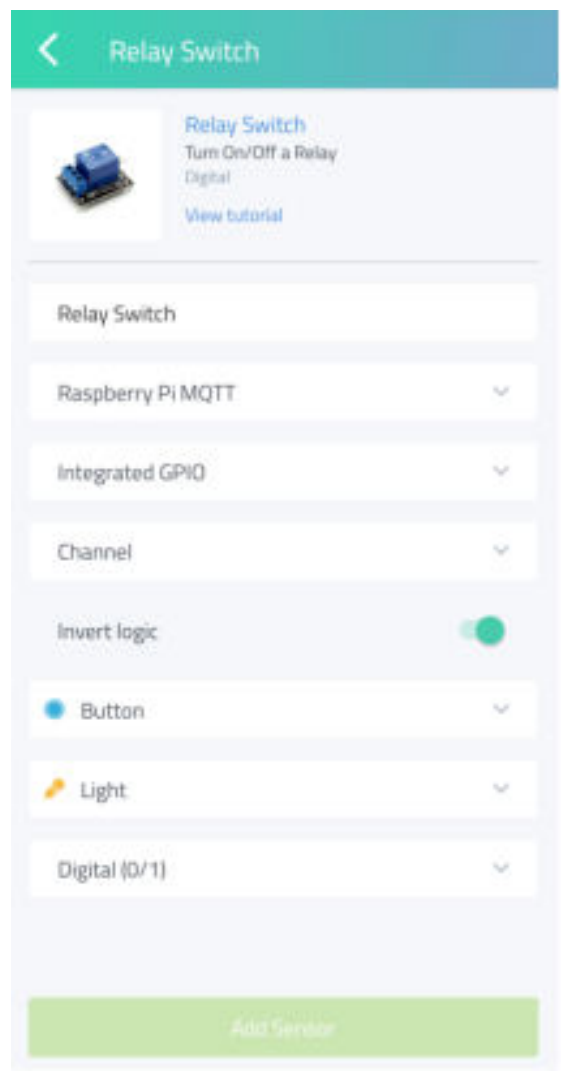

Gambar 13. Memasukkan Perintah Relay

Yang perlu diganti atau dirubah disini adalah "Relay Switch" diganti dengan
"Nama yang diinginkan" dan "Channel" diganti dengan pin GPIO yang digunakan, lalu simpan dengan dengan cara tekan "Add Sensor". Untuk Relay 1 diberi nama "Lampu 1" dengan channel 18, Relay 2 diberi nama "Lampu 2" dengan channel 17, Relay 3 diberi nama "Lampu 3" dengan channel 27, dan Relay 4 diberi nama "Lampu 4" dengan channel 22.

Pengujian pada Raspi diperlukan untuk pembagian pin GPIO yang nanti akan memicu Relay agar dapat mengoperasikan instalasi listrik rumah tangga yang bertegangan AC 220 Volt.

Pengujian melalui komputer dilakukan dengan cara hanya menghubungkan komputer dengan internet, kemudian membuka website cayenne.mydevices.com

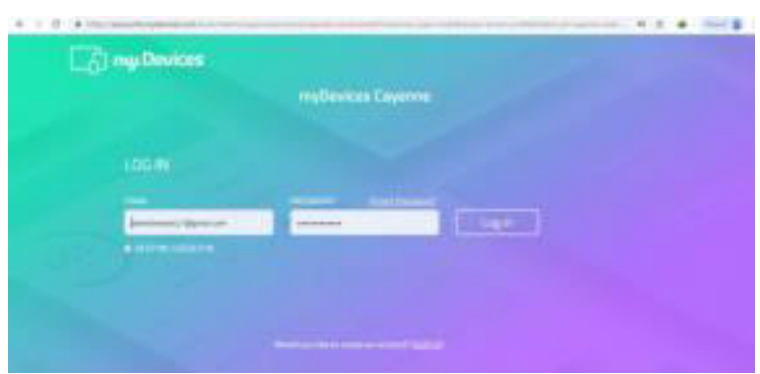

Gambar 14. Login Cayenne melalui Komputer

Berikut merupakan hasil pengujian Raspi melalui smartphone dan komputer:

Tabel 1. Hasil Pengujian Pin GPIO Raspi melalui Smartphone

\begin{tabular}{ccccc}
\hline No & $\begin{array}{c}\text { Relay di } \\
\text { Smartphone } \\
\text { (Cayenne) }\end{array}$ & Kondisi Relay & Pin Raspi & $\begin{array}{c}\text { Tegangan di Pin } \\
\text { GPIO Raspi (Vdc) }\end{array}$ \\
\hline 1 & Lampu 1 & OFF & GPIO 18 & 0 \\
& & ON & & 5,1 \\
2 & Lampu 2 & OFF & GPIO 17 & 0 \\
& & ON & & 5,1 \\
3 & Lampu 3 & OFF & GPIO 27 & 5,1 \\
4 & ON & OFF & GPIO 22 & 0 \\
& Lampu 4 & ON & G,1
\end{tabular}




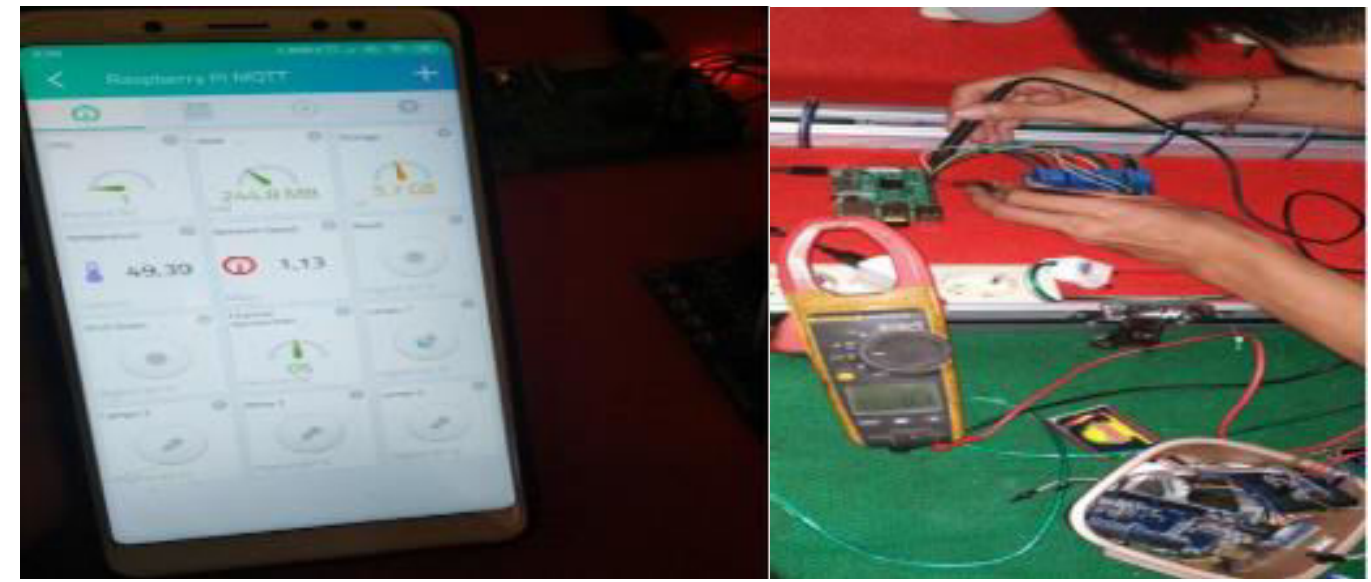

Gambar 15. Pengujian Raspi melalui Smartphone

Tabel 2. Hasil Pengujian Pin GPIO Raspi melalui Komputer

\begin{tabular}{ccccc}
\hline No & $\begin{array}{c}\text { Relay di Komputer } \\
\text { (Website) }\end{array}$ & Kondisi Relay & Pin Raspi & $\begin{array}{c}\text { Tegangan di Pin } \\
\text { GPIO Raspi (Vdc) }\end{array}$ \\
\hline 1 & Lampu 1 & OFF & GPIO 18 & 0 \\
& & ON & & 5,1 \\
2 & Lampu 2 & OFF & GPIO 17 & 5,1 \\
& & ON & & 0 \\
3 & Lampu 3 & OFF & GPIO 27 & 5,1 \\
& & ON & & 0 \\
4 & Lampu 4 & OFF & GPIO 22 & 5,1 \\
\hline
\end{tabular}

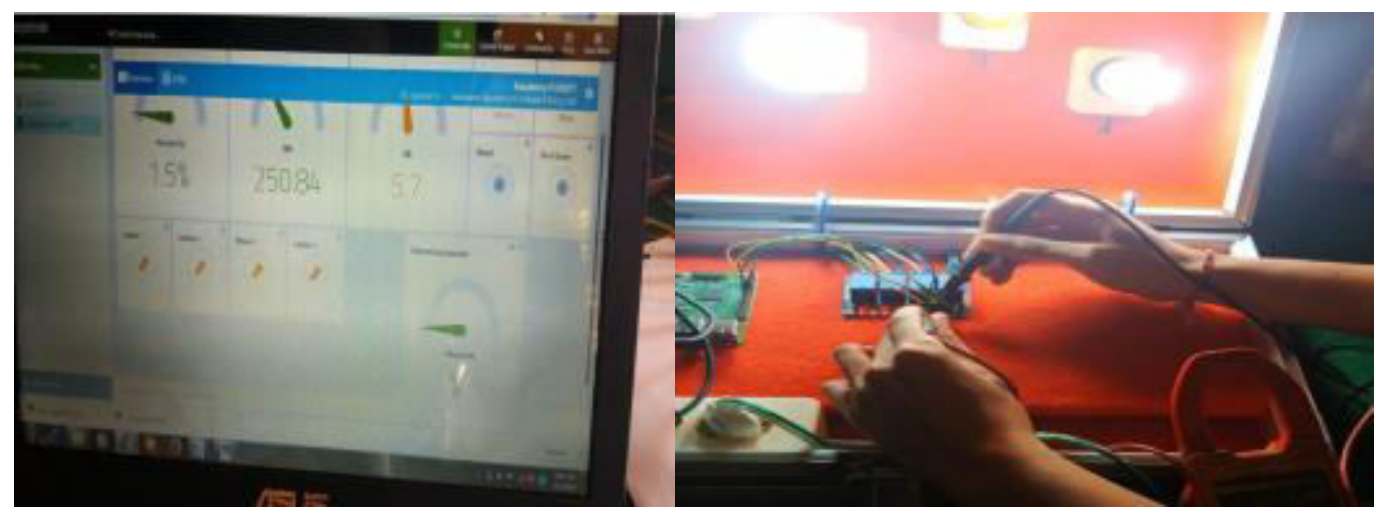

Gambar 16. Pengujian Raspi melalui Komputer

Pada pengujian Relay, yang di ukur adalah output dari Relay, yaitu merupakan tegangan AC (bolak-balik). Tegangan AC ini digunakan sebagai penyuplai untuk peralatan listrik rumah tangga yang akan dioperasikan (dalam hal ini berupa lampu).

Berikut merupakan hasil pengujian Relay melalui smartphone dan komputer:

Tabel 3. Hasil Pengujian Relay melalui Smartphone 
ISSN 2089-8673 (Print) | ISSN 2548-4265 (Online) Volume 9, Nomor 3, Desember 2020

\begin{tabular}{|c|c|c|c|c|}
\hline No & $\begin{array}{c}\text { Relay di } \\
\text { Smartphone } \\
\text { (Cayenne) }\end{array}$ & Kondisi Relay & $\begin{array}{l}\text { Output } \\
\text { Relay }\end{array}$ & $\begin{array}{l}\text { Tegangan di Pin } \\
\text { Output Relay (Vac) }\end{array}$ \\
\hline 1 & Lampu 1 & $\begin{array}{l}\text { OFF } \\
\text { ON }\end{array}$ & Relay 1 & $\begin{array}{c}0 \\
227\end{array}$ \\
\hline 2 & Lampu 2 & $\begin{array}{l}\text { OFF } \\
\text { ON }\end{array}$ & Relay 2 & $\begin{array}{c}0 \\
228\end{array}$ \\
\hline 3 & Lampu 3 & $\begin{array}{l}\text { OFF } \\
\text { ON }\end{array}$ & Relay 3 & $\begin{array}{c}0 \\
227\end{array}$ \\
\hline 4 & Lampu 4 & $\begin{array}{l}\text { OFF } \\
\text { ON }\end{array}$ & Relay 4 & $\begin{array}{c}0 \\
230\end{array}$ \\
\hline
\end{tabular}

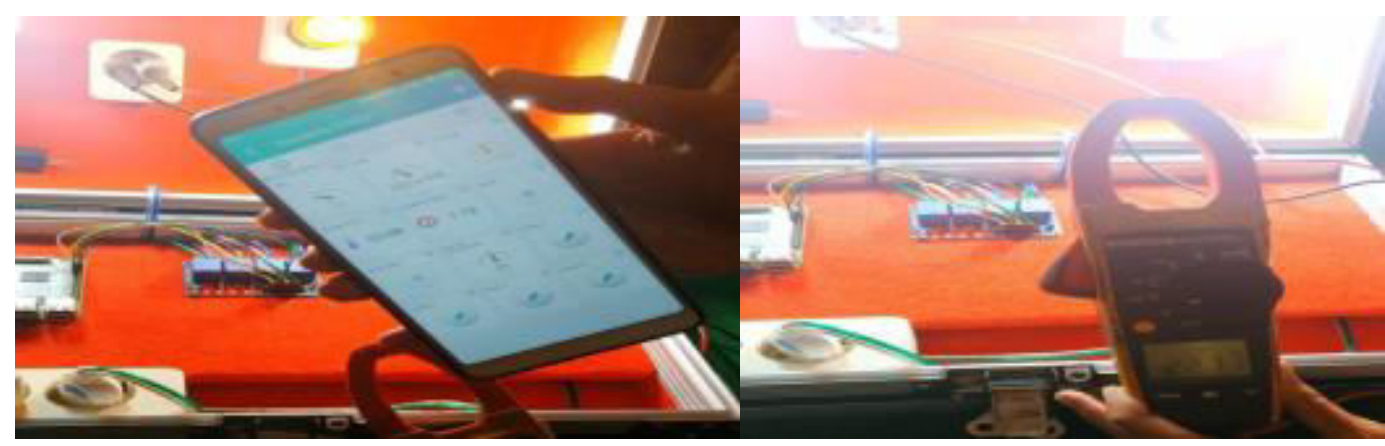

Gambar 17. Pengujian Relay melalui Smartphone

Tabel 4. Hasil Pengujian Relay melalui Komputer

\begin{tabular}{ccccc}
\hline No & $\begin{array}{c}\text { Relay di Komputer } \\
\text { (Website) }\end{array}$ & Kondisi Relay & $\begin{array}{c}\text { Output } \\
\text { Relay }\end{array}$ & $\begin{array}{c}\text { Tegangan di Pin } \\
\text { Output Relay (Vac) }\end{array}$ \\
\hline \multirow{2}{*}{1} & Lampu 1 & OFF & Relay 1 & 0 \\
& & ON & & 229 \\
2 & Lampu 2 & OFF & Relay 2 & 0 \\
& & ON & & 228 \\
3 & Lampu 3 & OFF & Relay 3 & 0 \\
& & ON & & 229 \\
4 & Lampu 4 & OFF & Relay 4 & 0 \\
& & ON & & 227 \\
\hline
\end{tabular}

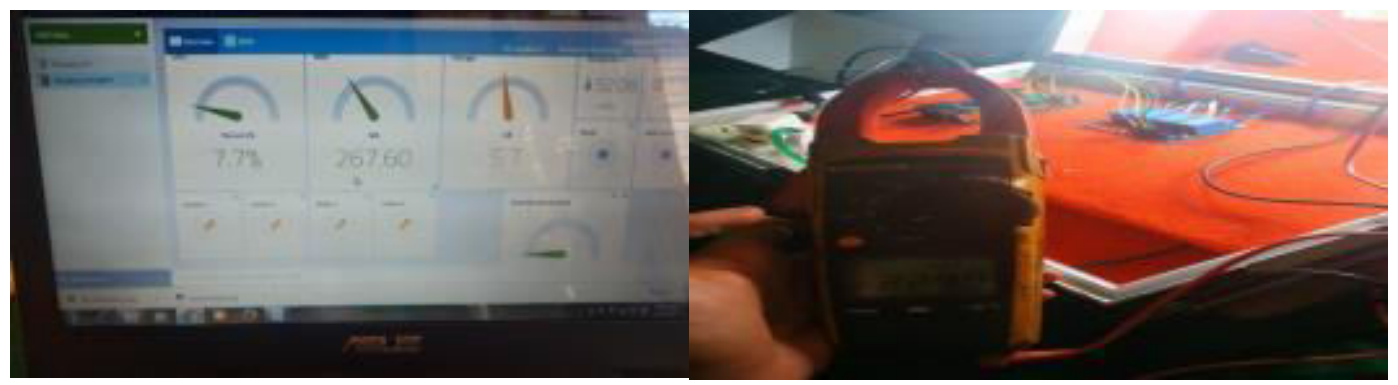

Gambar 18. Pengujian Relay melalui Komputer

Tahap pengujian terhadap rangkaian Raspi dan Relay telah selesai dilaksanakan dan hasilnya sudah sesuai dengan perancangan, untuk tahap selanjutnya 
adalah pengujian keseluruhan sistem yang dilakukan sebagai berikut:

Pengujian melalui smartphone dan juga melalui komputer dilakukan dengan cara mengoperasikan tombol atau sakelar yang telah dibuat. Saat kondisi tombol atau sakelar pada layar smartphone dan layar komputer menyala itu menandakan bahwa output pada Relay tersebut bertegangan atau dalam posisi ON, sedangkan saat kondisi tombol padam menandakan dalam posisi OFF atau tidak bertegangan.

Pada hasil pengujian keseluruhan sistem yang telah dilakukan, menunjukkan bahwa perancangan dan pembuatan alat sistem kendali jarak jauh peralatan listrik rumah tangga sudah berjalan dengan baik. Lampu dapat menyala dan padam sesuai dengan perintah yang diberikan baik melalui smartphone maupun komputer.

\section{SIMPULAN}

Dari perancangan dan pembuatan alat sistem kendali jarak jauh peralatan listrik rumah tangga dapat diambil kesimpulan, yaitu :

1. Berdasarkan data hasil pengujian yang telah dilakukan, alat yang dirancang sudah bekerja dengan baik, yaitu lampu dapat menyala dan padam sesuai dengan perintah yang diberikan baik melalui smartphone maupun komputer.

2. Rata-rata tegangan listrik yang dihasilkan pin GPIO Raspi (Vdc) pada saat lampu menyala sebesar 5,1 Volt dan 0 Volt, sehingga hal ini dapat mengaktifkan dan menonaktifkan Relay yang terhubung dengan peralatan listrik rumah tangga (lampu).

3. Rata-rata tegangan listrik yang dihasilkan pin output Relay (Vac) pada saat lampu menyala sebesar 228,12 Volt dan 0 Volt, sehingga hal ini dapat menyalakan dan memadamkan peralatan listrik rumah tangga (lampu).

\section{REFERENSI}

[1] Muzawi R, Efendi $Y$, Sahrun N. PROTOYPE PENGENDALIAN LAMPU JARAK JAUH DENGAN JARINGAN INTERNET BERBASIS INTERNET OF THINGS (IOT) MENGGUNAKAN RASPBERRY Pi 3. J Inf. 2018;3(1):1-
6.

[2] Muharam $M$, Latif $M$, Saputra $M$. SISTEM KENDALI JARAK JAUH BERBASIS WEB UNTUK SISTEM RUMAH PINTAR. J Nas Tek Elektro. 2018;7(3).

[3] Sulaiman OK, Widarma A. SISTEM INTERNET OF THINGS (IOT) BERBASIS CLOUD COMPUTING DALAM CAMPUS AREA NETWORK. In: Seminar Nasional Fakultas Teknik UISU-Medan. 2017.

[4] Udy Ariawan K, Sutaya IW. PENGEMBANGAN PAPAN PENGUMUMAN DIGITAL MENGGUNAKAN XIBO DAN RASPBERRY Pi (STUDI KASUS: JURUSAN TEKNIK ELEKTRO). In: Seminar Nasional Riset Inovatif (SENARI). Bali: LPPM Universitas Pendidikan Ganesha; 2017.

[5] Alexander D, Turang O. PENGEMBANGAN SISTEM RELAY PENGENDALIAN DAN PENGHEMATAN PEMAKAIAN LAMPU BERBASIS MOBILE. In: Seminar Nasional Informatika UPN Veteran Yogyakarta. 2015. p. 75-85.

[6] Saputri TA, Sutomo B. SMART HOME RASPBERRY Pi DENGAN FRAMEWORK CAYENNE BERBASIS INTERNET OF THINGS (IOT). In: Seminar Nasional Teknologi dan Bisnis IIB Darmajaya Bandar Lampung. 2018. p. 112-9. 